\title{
Materials Selection and Tests for Precise Execution of Foundry Molds Designed to Geopolymer Casts
}

\author{
Kinga Łopata ${ }^{1}$, Kinga Korniejenko ${ }^{1}$, Brian Azzopardi ${ }^{2}$, and Michat Łach $^{1^{*}}$ \\ ${ }^{1}$ Cracow University of Technology, Faculty of Material Engineering and Physics, Institute of \\ Materials Engineering, Warszawska 24, 31-155 Cracow, Poland \\ ${ }^{2}$ Malta College of Arts, Science and Technology, MCAST Energy Research Group, Triq Kordin, \\ Raћal Ġdid, 2001, Paola, Malta
}

\begin{abstract}
The paper presents the results of research on the selection of material for molds intended for geopolymer castings as well as an appropriate technological process for the preparation of such castings. Three silicons with different elasticity and hardness of 30,40 and 60Sh were tested. The above-mentioned rubbers were used to make one-piece open molds and test the performance of each material. A model having several details and a small flat surface was chosen for the replica. Based on this variation in the wall structure, it was possible to assess the accuracy of mapping, both small elements and straight cast planes. In the prepared forms 10 tests of geopolymer casting were carried out to develop the best technological process. The appropriate result was achieved when the molds covered with the divider were flooded with raw material by vibrating them on a vibrating table, and then allowed to react for an hour for free mass components and leaking gases to the surface. After a set time, the compaction was carried out again to more accurately eliminate the resulting air bubbles. The effect of this method is to obtain a cast with precisely mapped details and a smooth even surface, and almost complete elimination of air bubbles from representative surfaces.
\end{abstract}

\section{Introduction}

Contemporary culture is developing mainly in the era of artificial materials and polymer materials. However, nowadays it is increasingly leaning towards environmentally friendly solutions. Public awareness and sensitivity are increasing concerning harmful, non-recycled and non-renewable raw materials. We are trying to rebuild the cultural heritage and reconstruct synthetic civilization more and more willingly reaching towards natural products and inspired by natural building materials.

Return to nature becomes a fashionable leitmotif. Raw stone and untreated wood are eagerly used by current designers and welcomed to a wide audience. In the era of modern composites and the growing awareness of the importance of ecological solutions,

\footnotetext{
*Corresponding author: michal.lach@pk.edu.pl
} 
geopolymers - intriguing materials with a polymer structure and natural composition - have also expanded. The developed recipe is no longer a mystery, and simple to reproduce and environmentally friendly building material is being distributed on an increasingly wide scale. This specific mass is finding newer fields of application [1-7]. High strength properties and unusual thermal resistance make it possible to use geopolymers in numerous fields of industry, construction and art.

Due to the high resistance of the material, it is not easy to process. The intersected sections show the structure of the mass interior with closed air pores. Wall surfaces are not perfectly smooth, they contain cut marks left by the tool. Due to the inevitable shortcomings in the treatment of hard rock mass, work on the development of casting technology is evident.

There are also geopolymer predispositions in creating complex shapes. Their good funnel properties open a wide field for creating more or less artistic details with application in architecture and art. Using these properties, we can close and capture the original shape in a properly prepared form after it has solidified.

Reconstruction of historic buildings is another area where the introduction of molded geopolymer masses is currently enjoying great revaluation. This includes architectural elements, reconstruction of sculptures and various types of constructions and reinforcements of figures based on composite blends. Prague Academy of Sciences has extensive experience in this matter, which describes its practice with geopolymer materials achieved in cooperation with the School of Sculpture and Reconstruction and the Museum of Art in Prague [1]. It is worth mentioning here various examples that seem interesting, because they illustrate well each field of application: renovation of building structures, reconstruction of sculpture strengthening and reproductions of damaged figures. The first example is the repair of buildings, specifically the gate of the rock city of Adrspach in the Czech Republic, a facility located just off the Polish border. The Gothic gate is the main entrance to the beautiful landscape park, where we can admire soaring rock forms consisting of plate sandstone. Located on the Sudeten forest, the floors naturally form tight mazes topped with gothic gates. The monumental entrance, which is part of the rock cliffs, was erected in 1839, during the reign of Baron Ludvik Karel Nadherny. However, under the influence of time and increasing heights, the sandstone was heavily damaged, especially at the seam between the stone rocks. There is also considerable instability of the upper support. Details of the defects are visible in the form of gaps resulting from material erosion and penetration of devastating vegetation [1]. For the reconstruction of the gate, a composite of geopolymeric mass based on kaolinite with the addition of local sand was used. The material in the form of dense paste was applied in the gaps between the slabs and the gaps of the rock massif blocks. Geopolymer has proved to be an excellent choice for the reinforcing material, because it does not contain limestone substances that have been excluded from use among other natural preservatives. After two years of observation, no damage or disturbing changes in the structure of the building were noticed, and despite the humid environment, the bond between the welded parts is in perfect condition [1].

The second example is the reconstruction of the seventeenth-century figure "Virgin Maria with child Jesus and John Baptist", author G.M. Mazza, which is the property of the National Art Gallery in Prague. The figure is made of terracotta, and for additional strengthening from the inside, it was filled with sandstone. It also compensates for the difference in wall thickness of the target material. During maintenance, the figure required the structure to be opened to allow access to the interior and to disassemble the parts undergoing reconstruction. A geopolymer was chosen for the material strengthening the statue's interior. The original limestone binder filling was previously excluded from use.

Due to the plasticity of the geopolymer mass, ensuring easy application and access to any difficult fragment, it is also a great alternative to popular supports from metal 
structures. The reconstruction of the cited monument turned out to be particularly difficult and required careful planning of the next steps of the procedure. The division of the figure into parts was determined specially and proceeded according to the original modular line. Gradually, the entire rear part of the statue was dismantled and all kinds of materials combining the figurine were extracted from it. Only the inner part of the terracotta statue has been repaired with the geopolymer composite [1].

The third example corresponding to the reproduction of monuments is the use of a geopolymer as a replacement for casting porcelain figures. A copy of the sphinx figurine was made of the geopolymer mass containing porcelain powder. The decorative replica concerned the original pagoda-shaped Delphi vase, topped with four small sphinx figurines at the top. One of them was faithfully reproduced using a geopolymer mass cast in a mold. The finished product was then finished painting with appropriate graphics according to the original pattern [1]. Based on the examples presented above, we can see that the current technique learns to use geopolymer properties. We draw knowledge from the ancients by discovering and learning about their amazing buildings and what they hide behind their stone walls. Powerful pyramids built of geopolymer blocks, cast vases, complicated vessels, statues and many other indescribable examples inspire us, as modern artists, to explore ancient ecological technology. We try to imitate the legacy of natural and friendly aluminosilicate materials left behind. Modern technology is developing strongly in this area, geopolymers find many applications in the reproduction of sculptures and buildings, in architecture and art but also industrial areas for the production of structural elements and tools for complex applications and work in demanding conditions. Their properties give technologists a wide range of applications, enabling the creation of increasingly new composites based on geopolymer binders. Inspiring discoveries spread the potential of geopolymers, stimulating scientists to undertake innovative research and a venture worth escalating.

Following the trend of searching for materials for pro-ecological applications in architecture and art, in this work, it was undertaken to conduct experiments towards highly promising geopolymer materials. Attempts to have been made to cast raw materials, with particular emphasis on compositions of complex shapes that are used in various areas of culture. The ultimate effect of the work was to choose the right material dedicated to molds intended for casting geopolymer materials.

\section{Materials and methods}

For the preparation of castings, a geopolymer mass was used, which was prepared based on metakaolin activated with a $10 \mathrm{M} \mathrm{NaOH}$ solution with an aqueous solution of sodium silicate (water glass). The ratio of $\mathrm{NaOH}$ solution to water glass was 1: 2 . The ingredients were mixed in amounts of $1 \mathrm{~kg}$ metakaolin and $500 \mathrm{ml}$ solution respectively. 10 different casting tests were carried out in succession, slightly changing the process method, without interfering with the composition and proportions of the mass. This methodology allowed accurate observation of the results that occurred in the casting with small changes in the parameters of the casting process.

The molds for castings were made of carefully selected silicones. The first of the materials was a two-component silicone from the Mold Star series (manufacturer Kauposil) with a hardness of $30 \mathrm{Sh}$ in blue. The product is practical in casting because it has low viscosity and in most cases does not require venting. The manufacturer dedicates this material to plaster, wax, synthetic resin and concrete castings. It guarantees high tear resistance and long life. The predictable life of the mold with proper storage is impressively high, as it has been determined to be about 10 years. 
The second silicone, selected from the manufacturer's offer Gumosil, was a gray rubber with an increased hardness of $60 \mathrm{Sh}$ and high mechanical strength. It has increased resistance to tearing and stretching and high resistance to chemicals and high temperatures. It is particularly recommended for industrial and architectural castings, concrete products, ceramics and plastering works.

The third silicone material was the Xiameter RTV-4234-T4 molding silicone, very popular on the European market. It is designed for casting prototype forms in the VaccumCasting technique from polyurethane, epoxy, polyester and other reactive resins. The hardness of the silicone is centered compared to the above two products and amounts to $40 \mathrm{Sh}$, respectively. The colorless color is an undoubted advantage of the product. Transparency facilitates observation of mass spreading while filling the mold. As a master model based on which geopolymer replicas were created, an object with a rectangular shape and dimensions of $12.2 \times 8.8 \times 2.8 \mathrm{~mm}$ was selected. The model had perpendicular walls, based on which it was easy to determine possible dimensional deviations of the casting sides.

The model's walls are entirely covered by a geometric pattern consisting of rows of small squares. The pattern forming the truss of narrow grooves and projections was used to determine the precision of casting detailed elements. The upper wall of the model has a symmetrical bevel to the center and a circular cutout no longer containing any grooves. The smooth surface of the cutout allowed for accurate interpretation of the mapping of simple planes of the cast mass.

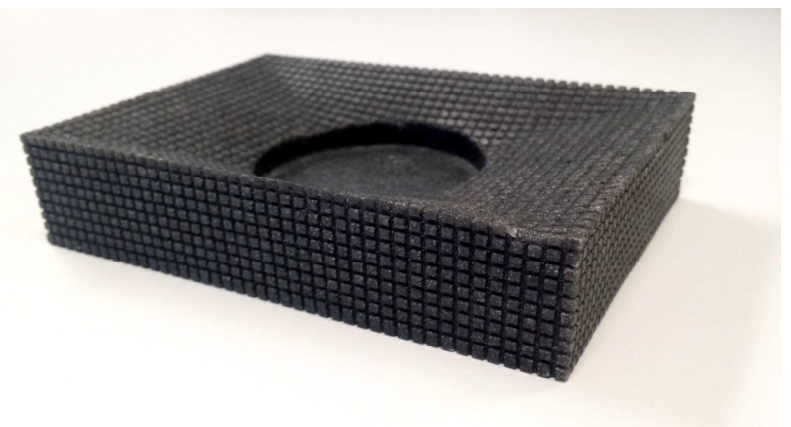

Fig. 1. The master model replicated object based on which forms were made.

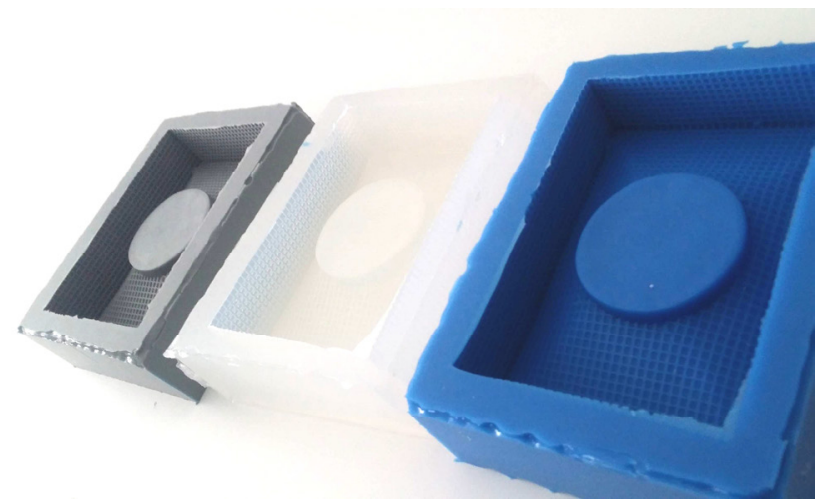

Fig. 2. Silicone molds made; gray - Gumosil 60Sh silicone; colorless -silicone Xiameter RTV-4234T4 40Sh, blue - Kauposil 30Sh. 


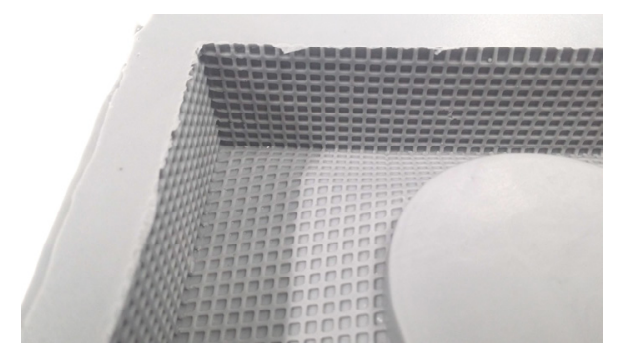

Fig. 3. Gray form - Gumosil 60Sh silicone, accurate reproduction of the replicated master surface of the model.

Several tests were carried out on casting a geopolymer mass with a constant composition into three silicone molds, each time changing the process parameters. Parameters such as venting (vibration), hardening in a vacuum chamber, time from flooding to vibrating and hardening, use of a separating agent were changed.

Based on the tests and experiments carried out, the most advantageous method of making geopolymer mass castings in open molds was verified. It has been proven that the visual effect of the surface is well influenced by the use of a mold separator, whereas it is unfavorable to vent the mass in a vacuum. Blisters occurring on the outer surface tend to accumulate with complicated details and inlets, while the straight plane practically does not contain them. It is probably related to the continuous reaction of silicone with the geopolymer mass on the contact surface of the mold, which is developed in the case of small elements. However, it is possible to reduce the number of cumulative bubbles by using vibrating machines in the casting process and leaving the mixed mass to wait before putting it into the heating furnace. The most optimal effect was obtained when the cast mass was vibrated, left for an hour and the mixture vibrated again. Figure 4 below presents geopolymer castings with a significant number of surface defects. This is the result of incorrect selection of parameters of the casting process. Figure 5 shows an example of castings without flaws.

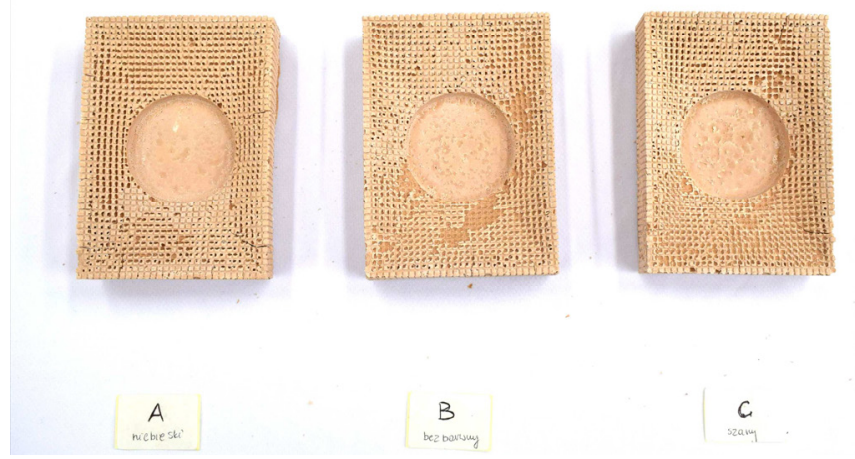

Fig. 4. Geopolymer castings with visible surface defects. 


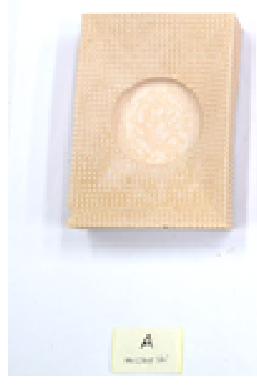

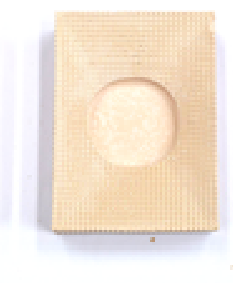

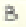

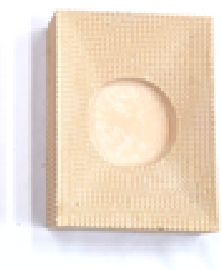

$c$

Fig. 5. Geopolymer castings without visible surface defects and air bubbles.

On the example of three molds made of silicones of different hardness, it can be stated that the type of material used for the mold does not affect the appearance of the resulting casting. However, there are visible differences when working with the mold during the geopolymer casting process. Definitely the hardness of the silicone is important when removing hardened casting from the mold. It is best to cast a blue silicone cast with less hardness and high elasticity. The worst of the stiff gray form.

In the next stage of research, having selected material for molds and parameters of the casting process, attempts were made to confirm the results obtained by creating a useful product based on geopolymers, produced in two-part forms. It was decided to create a candle holder, the visualization of which is shown in Figure 6. Next to Figure 6, finished products obtained from colored geopolymer mass are also presented.
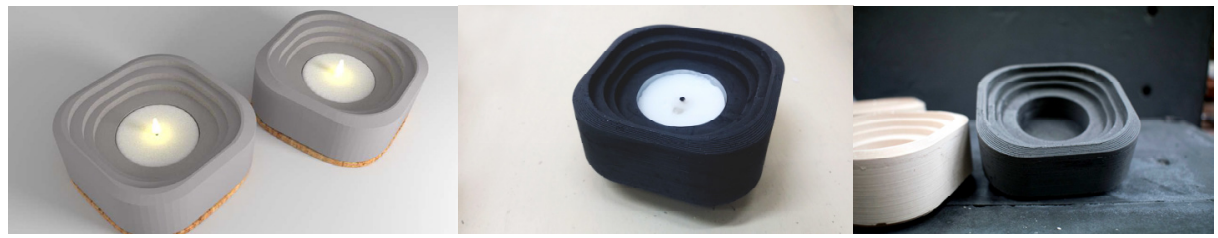

Fig. 6. Candlestick visualization.

The final castings obtained are characterized by the high precision of shape mapping and small details. Due to the use of the developed casting method and the appropriate arrangement of the mold, it was possible to virtually eliminate blisters from the externally visible surfaces of the model. The gases have escaped up in the highest zone, which in this case was the bottom of the product. The surface left in this way can only undergo additional treatment. Any wall finishing can be done by sanding or leveling. The unsightly effect of bubble accumulation is not eliminated, because it is a natural feature of geopolymer materials. Therefore, when undertaking work with these materials, one should be aware of the reactive structure and shortcomings arising during the process. By designing the right arrangement of molding tools, technologists can manipulate air bubbles to a certain extent by directing them to a specific plane of the object.

\section{Summary}

The research consisting of the selection of appropriate parameters of the geopolymer mass casting process for molds and the selection of material for molds allowed to formulate the following conclusions:

1. The visual effect of the final surface is well influenced by the use of a mold separator, whereas it is unfavorable to vent the mass in a vacuum. Blisters occurring on external 
surfaces tend to accumulate with complex details and inlets, while the flat plane practically does not contain them.

2. There is a possibility of reducing the number of accumulated bubbles by using vibrating machines in the casting process and leaving the created mass to wait before putting it into the heating chamber for hardening. The most optimal effect was obtained when the cast mass was vibrated, left for an hour and the mixture vibrated again.

3. On the example of three molds made of silicones of different hardness, it can be stated that the type of material used for the mold does not affect the appearance of the obtained casting. However, there are visible differences when working with the mold during the geopolymer casting process. Definitely, the hardness of the silicone is important when removing hardened casting from the mold.

Due to their reactions and the waste materials used, geopolymer materials are reactive materials, and they contain various types of digestion processes, which are often accompanied by gas evolution. It is not an art to eliminate the reactive nature of the material by force. But the alternative of art can also be a reversal of the direction of technological activities and the use of a defect, which is a porous structure in the form of a natural feature and an interesting asset. There are many possible solutions because aesthetics is a relative concept.

This work has been financed by Polish National Agency for Academic Exchange under the International Academic Partnership Programme within the framework of the grant: E-mobility and sustainable materials and technologies EMMAT(PPI/APM/2018/1/00027).

\section{References}

1. https://www.irsm.cas.cz/materialy/oddeleni/1/prezentace/Statue_2110.pdf (May, 2020)

2. J. Davidovits, Geopolymer Chemistry and Applications 4th Edition (Geopolymer Institute, Saint-Quentin, 2015)

3. J. Novotny, VIII Konferencja Odlewnicza Technical, 111-118 (2005) (in Polish)

4. http://phys.org/news167306601.html (May, 2020)

5. J. Mikuła, Rozwiazania proekologiczne (Wydawnictwo Politechniki Krakowskiej, Kraków, 2014)

6. https://www.davidovits.info/my-encounter-with-the-venus-from-dolni-vestonice-a25000-years-old-geopolymer-ceramic/ (May, 2020)

7. J. Davidovits, R. Davidovits,'99 Geopolymer International Conference Proceedings, (Geopolymer Institute, Saint-Quentin, 1999) 